\title{
Avaliação nutricional de estratégias de suplementação para bovinos de corte durante a estação da seca ${ }^{1}$
}

\author{
Eduardo Henrique Bevitori Kling de Moraes $^{2}$, Mário Fonseca Paulino ${ }^{3}$, Sebastião de Campos \\ Valadares Filho ${ }^{3}$, Kamila Andreatta Kling de Moraes ${ }^{4}$, Edenio Detmann ${ }^{3}$, Marcos Gonçalves \\ de Souza ${ }^{5}$
}

${ }^{1}$ Pesquisa parcialmente financiada pelo CNPq e pela FAPEMIG.

2 Departamento de Zootecnia/ICAA/UFMT, Sinop-MT, CEP: 78557-267. Pesquisador do INCT-CA.

${ }^{3}$ Departamento de Zootecnia/UFV, Viçosa, MG, CEP: 36570-000. Bolsista do CNPq.

${ }^{4}$ Departamento de Zootecnia/ICAA/UFMT, Sinop-MT, CEP: 78557-267.

${ }^{5}$ Doutorando, UNESP, Jaboticabal-SP, CEP:14884-900

RESUMO - Objetivou-se avaliar o efeito da frequência de oferta de suplementos proteicos sobre as características nutricionais de bovinos de corte em pastejo durante o período de seca. Utilizaram-se cinco novilhos mestiços Nelore nãocastrados, com peso médio inicial de $290 \mathrm{~kg}$, fistulados no esôfago e rúmen e distribuídos em delineamento quadrado latino $5 \times 5$. A área experimental foi composta de cinco piquetes de Brachiaria decumbens, cada um com 0,40 hectare. O experimento foi composto de cinco períodos experimentais de 15 dias, com os sete primeiros dias destinados à adaptação dos animais. As estratégias estudadas foram autocontrole de consumo e oferta de suplementos (1,0 kg/dia) em três frequências: 3 vezes/semana (às segundas, quartas e sextas-feiras), 5 vezes/semana (de segunda a sexta-feira), 6 vezes/semana (de segunda a sábado) e diariamente. Não houve efeito das frequencias de suplementação sobre os consumos expressos em kg/dia ou \% PV. A frequência de suplementação teve efeito nas digestibilidades aparentes total e ruminal da MS e da PB, que foram maiores nos animais do grupo autocontrole. Os valores médios de $\mathrm{pH}$ observados no dia em que os animais não receberam suplemento foram de: $6,54 \pm 0,13 ; 6,48 \pm 0,15$ e 6,61 $\pm 0,07$, respectivamente, para as frequências 3 vezes/semana, 5 vezes/semana e 6 vezes/semana. A concentração do $\mathrm{NH}_{3}$ foi 14,65 \pm 5,78; $13,57 \pm 5,30$ e 15,30 \pm 4,98 mg/dL de líquido ruminal, respectivamente, para as frequências 3 vezes/semana, 5 vezes/semana e 6 vezes/semana nos dias em que os animais não receberam suplemento. As eficiências microbianas e as concentrações de nitrogênio na urina e no soro sanguíneo são afetadas pelas estratégias estudadas e maiores nos animais alimentados com suplemento autocontrole.

Palavras-chave: consumo, digestibilidade, frequência de suplementação, suplementação autocontrole

\section{Nutritional evaluation of supplementation strategies for beef cattle during the dry season}

\footnotetext{
ABSTRACT - The objective of this study was to evaluate the effect of the frequency of protein supplementation on the nutritional characteristics of beef cattle during the dry season. Five Nellore crossbred steer were used $290.0 \mathrm{~kg} \mathrm{LW}$, fistulated in the rumen and esophagus, distributed in a $5 \times 5$ Latin square design. The experimental area consisted of five 0.40 ha Brachiaria decumbens paddocks. The experiment consisted of five 15-day experimental periods, with the first seven days for the animals to adapt. The strategies studied were: self-feed supplementation and supplementation $(1.0 \mathrm{~kg} / \mathrm{animal} / \mathrm{day})$ offered at three frequencies: three times/week (Monday, Wednesday and Friday), five times/week (Monday to Friday) and six times/week (Monday to Saturday) and daily. There were no effects of the different strategies on the intake expressed in $\mathrm{kg} / \mathrm{day}$ or LW percentage. The supplementation frequency affected the total DM apparent digestibility and ruminal crude protein apparent digestibility that were higher in the self-feed supplementation group. The mean $\mathrm{pH}$ values, observed on the day when the animals were not supplemented were: $6.54 \pm 0.13 ; 6.48 \pm 0.15$ and $6.61 \pm 0.07$, respectively for, the frequencies 3 times/week, 5 times/ week and 6 times/week. The $\mathrm{NH}_{3}$ concentration was: $14.65 \pm 5.78 ; 13.57 \pm 5.30$ and $15.30 \pm 4.98 \mathrm{mg} / \mathrm{dL}$ ruminal liquid, respectively, for the frequencies 3 times/week, 5 times/week and 6 times/week, on days without supplementation. The microbial efficiency and nitrogen concentrations in the urine and serum are affected by the strategies studied and are higher in the animals fed self feed supplementation.
}

Key Words: digestibility, frequency of supplementation, intake, self-feed supplementation

Recebido em 25/8/2008 e aprovado em 20/2/2009.

Correspondências devem ser enviadas para: edukling@ufmt.br 


\section{Introdução}

Durante a estação seca do ano, as gramíneas tropicais apresentam baixo valor nutritivo e teor proteico inferior ao valor mínimo de 7,0\% para que os microrganismos tenham condições de utilizar os substratos energéticos fibrosos da forragem ingerida (Lazzarini et al., 2009). Como o desempenho animal nessas pastagens não é satisfatório, é necessário o fornecimento de suplementos concentrados, considerando sempre o ponto de vista técnico-econômico. A correção das deficiências nutriticionais do pasto via suplementação permite melhores desempenhos e propicia a redução do ciclo de produção e da idade de abate dos animais.

A viabilidade da pecuária de corte depende diretamente da economia em escala, pois opera com margens de lucro mais reduzidas. Desta forma, a busca pela redução dos custos de produção deve depender não apenas do menor custo de alimentação, mas também de estruturas mais simples em termos de transporte e de distribuição dos suplementos.

Assim, a utilização de estratégias de suplementação do tipo autocontrole de consumo ou infrequente pode ser uma alternativa de manejo de suplementos em sistemas de suplementação de bovinos a pasto e possibilita ao produtor redução de gastos com mão-de-obra e equipamentos para suplementação.

A redução na frequência de suplementação não prejudica o desempenho do animal e pode representar uma opção para o produtor visando principalmente à redução dos custos do fornecimento da alimentação (Canesin et al., 2007). Segundo Nolan \& Leng (1972), a reciclagem de $\mathrm{NH}_{3}$ absorvida no rúmen pode suportar padrões adequados no ambiente ruminal entre tempos de suplementação. A teoria mais aceita para a melhoria na eficiência de utilização da proteína seria que a suplementação em menor frequência estimularia a retenção do nitrogênio.

No entanto, os mecanismos nutricionais associados à manutenção do desempenho com a suplementação em intervalos de oferta não são ainda bem elucidados e necessitam investigações, principalmente nas condições tropicais. Desta forma, objetivou-se avaliar o efeito da frequência de suplementação sobre o consumo e a digestibilidade dos nutrientes e sobre os parâmetros ruminais de bovinos de corte em pastejo no período da seca.

\section{Material e Métodos}

O experimento foi conduzido no Setor de Bovinocultura de Corte/Zootecnia da UFV, no período da seca, entre os meses de junho e setembro de 2003 utilizando-se cinco novilhos mestiços Zebu, não-castrados, com peso médio inicial de 290 kg, fistulados no esôfago e no rúmen. A área experimental consistiu de cinco piquetes de 0,40 ha cada, formados com Brachiaria decumbens, providos de bebedouro e comedouro.

O experimento foi composto de cinco períodos experimentais com 15 dias de duração, de modo que sete dias iniciais foram destinados à adaptação dos animais. Avaliaram-se suplementos com mesma composição, fornecidos em quantidades equivalentes a $1,0 \mathrm{~kg} / \mathrm{animal} /$ dia, em três frequências semanais, em comparação a um suplemento do tipo autocontrole de consumo (Tabela 1).

Após a pesagem inicial, os animais receberam de forma aleatória os tratamentos: autocontrole e as quatro frequências de suplementação: três vezes/semana (segunda, quarta e sexta - 3 vezes), cinco vezes/semana (segunda a sexta - 5 vezes), seis vezes/semana (segunda a sábado - 6 vezes) e diariamente (7 vezes). Os suplementos foram oferecidos às $10 \mathrm{~h}$ na proporção de 1,0 kg/animal/dia e, ao final de sete dias, cada um recebeu a mesma quantidade de suplemento (7 kg/animal/semana).

A cada 20 dias, realizou-se a coleta de amostras da forragem nos piquetes, por meio do corte, a $10 \mathrm{~cm}$ do solo, de cinco áreas delimitadas por um quadrado metálico de 0,5 $\times 0,5 \mathrm{~m}$, escolhidas aleatoriamente em cada piquete experimental. Após a pesagem, as amostras de cada piquete foram pesadas e homogeneizadas. De cada amostra, retiraram-se duas alíquotas compostas: uma para avaliação da disponibilidade total de MS/ha e outra para análise das disponibilidades por hectare de MS de folha verde, folha seca, colmo verde e colmo seco.

As análises químico-bromatológicas e a DIVMS foram realizadas de acordo com descrições de Silva \& Queiroz (2002), com exceção das avaliações de FDN e FDA, que seguiram os métodos descritos por Mertens (2002) e Van Soest \& Robertson (1985), respectivamente.

Das amostras destinadas à estimação da disponibilidade total de MS de forragem, foi calculado o percentual de MS potencialmente digestível (MSpD) ofertada aos

Tabela 1 - Composição dos suplementos (\% MN)

\begin{tabular}{lcc}
\hline Ingrediente & \multicolumn{2}{c}{ Suplemento } \\
\cline { 2 - 3 } & Autocontrole & Frequência \\
\hline Mistura mineral & 4,0 & 4,0 \\
Fosfato bicálcico & 1,0 & 1,0 \\
Calcário calcítico & 1,0 & 1,0 \\
Ureia/sulfato de amônia (9:1) & 6,0 & 3,5 \\
Farelo de algodão & - & 30,0 \\
Farelo de trigo & 88,0 & 60,5 \\
\hline
\end{tabular}


animais. Esse resultado foi obtido pelo resíduo insolúvel em detergente neutro avaliado após incubação in situ das amostras por 144 horas, segundo a equação: MSpD $=0,98 \times(100-F D N)+(F D N-F D N i)$; em que: 0,98 = coeficiente de digestibilidade verdadeiro do conteúdo celular; FDNi=FDN indigestível. A avaliação qualitativa da forragem ingerida foi realizada pela extrusa esofágica coletada no quarto dia de cada período experimental.

Coletaram-se amostras de fezes entre o oitavo e $14^{\circ}$ dia do período experimental, seguindo distribuição: $8^{0}$

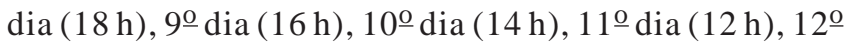

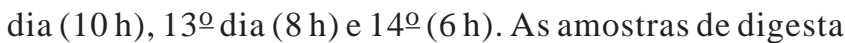
omasal foram coletadas no $9^{\circ}$ dia (16 h), $10^{\circ}$ dia (14 h), $12^{\circ}$ dia $(10 \mathrm{~h})$ e $13^{\circ}$ dia $(8 \mathrm{~h})$. Do material pré-seco, foram feitas amostras compostas individuais por período de coleta.

As coletas de urina e sangue e de líquido ruminal foram realizadas duas vezes ( 1 으 3 e $14^{\circ}$ dias) quatro horas após o fornecimento do suplemento. As leituras de $\mathrm{pH}$ do líquido ruminal foram realizadas imediatamente após a coleta por meio de potenciômetro digital. Para determinação de $\mathrm{NH}_{3}$, separou-se uma alíquota de $50 \mathrm{~mL}$, fixada com 1,0 mL de $\mathrm{H}_{2} \mathrm{SO}_{4}$ (1:1) e acondicionada em recipiente de plástico, identificada e congelada a $-20{ }^{\circ} \mathrm{C}$ para posterior análise laboratorial. A segunda coleta foi realizada no dia em que os animais sob suplementação 3 vezes/semana não receberem suplemento.

A excreção fecal foi estimada utilizando-se o óxido crômico, aplicado em dose única diária (10 g/animal), entre o $3^{\circ}$ e $12^{\circ}$ dia experimental, e calculada com base na razão entre a quantidade do indicador fornecido e sua concentração nas fezes.

As estimativas do consumo voluntário (CMS) e do fluxo de MS omasal (FMO) foram obtidas empregando-se como indicador interno a fibra em detergente neutro indigestível (FDNi), utilizando-se as seguintes equações:

$$
C M S=\frac{[(E F \times C I F)-I S]}{C I F O}+C M S S ; \quad F M O=\frac{E F \times C I F}{C I O}
$$

em que: $\mathrm{EF}$ = excreção fecal (kg/dia); $\mathrm{CIF}=$ concentração do indicador nas fezes $(\mathrm{kg} / \mathrm{kg})$; IS = indicador presente no suplemento (kg/dia); CIFO = concentração do indicador na forragem $(\mathrm{kg} / \mathrm{kg})$ e CMSS = consumo de matéria seca de suplemento (kg/dia); e CIO = concentração do indicador na digesta omasal (kg/kg).

As amostras de urina foram analisadas quanto aos teores de nitrogênio e de creatinina, empregando-se kits comerciais. Calculou-se o volume urinário diário pela relação entre a excreção diária de creatinina (EC), adotando-se como referência a equação proposta por Chizzotti et al. (2008) e sua concentração nas amostras spot: $\mathrm{EC}_{(\mathrm{mg} / \mathrm{kg} \mathrm{PV})}=32,27-0,01093 \times \mathrm{PV}$.
As análises de alantoína e de ácido úrico na urina foram realizadas conforme Fujihara et al. (1987), citados por Chen \& Gomes (1992). A excreção total de derivados de purina foi calculada pela soma das quantidades de alantoína e ácido úrico excretados na urina, expressas em mmol/dia. As purinas absorvidas ( $\mathrm{Y}, \mathrm{mmol} / \mathrm{dia}$ ) foram calculadas a partir da excreção de derivados de purinas (X, mmol/dia), pela equação proposta por (Verbic et al.,1990).

A síntese ruminal de compostos nitrogenados ( $\mathrm{Y}$, gNmic/dia) foi calculada considerando as purinas absorvidas (X, mmol/dia), utilizando-se a equação descrita por Chen \& Gomes (1992), com exceção da relação N purinas: $\mathrm{N}$ total das bactérias de 0,134 , conforme descrito por Valadares et al. (1999).

Os animais foram distribuídos em delineamento em quadrado latino $(5 \times 5)$, com cinco tratamentos e cinco períodos experimentais. A comparação entre tratamentos foi realizada por contrastes não-ortogonais: autocontrole versus frequência de suplementação; e os efeitos de ordem linear, quadrático e cúbico da frequência de suplementação. Em nenhuma das variáveis estudadas, detectou-se efeito de ordem cúbica, por isso, esses efeitos foram suprimidos da discussão. Para todos os procedimentos estatísticos, adotou-se $\alpha=0,10$.

\section{Resultados e Discussão}

A elevada maturidade fisiológica das plantas, a depleção do estrato folhoso do relvado, em razão de sua utilização pelos animais, e a baixa rebrotação do pasto, em virtude do período seco, resultaram em baixa qualidade nutricional da forragem (Tabela 2 ). Esse fato pode ser comprovado pelo teor de $\mathrm{PB}$, que sempre esteve abaixo do valor de 7,0\%, e ocorreu porque, na maturidade da planta, a atividade metabólica reduz, diminuindo a síntese de compostos nitrogenados nas folhas e colmos.

A digestibilidade in vitro da matéria seca média do pasto foi de $47,65 \%$ e é reflexo dos altos valores de FDNi e lignina decorrentes da avançada maturidade fisiológica das forrageiras. De fato, à medida que a idade fisiológica da planta avança, aumentam a concentração de carboidratos estruturais e a participação de lignina, que passam a corresponder a $80 \%$ dos carboidratos totais (Moraes et al., 2006).

As médias observadas para disponibilidade de MS total (MST), MS potencialmente digestível (MSpD), MS de folha verde (MSFOV), MS de folha seca (MSFOS), MS de colmo verde (MSCOV) e MS de colmo seco (MSCOS) do pasto foram, respectivamente, de 1,433 t/ha, 0,710 t/ha, 0,110 t/ha, 0,251 t/ha, 0,201 t/ha e 0,872 t/ha (Figura 1). 
A disponibilidade de MS potencialmente digestível, em virtude da grande participação de folhas secas e colmo secos, foi de apenas 49,59\%, que significa baixo estoque de energia potencialmente digestível para os animais.

Não houve efeito dos suplementos sobre os consumos expressos em kg/dia ou em \%PV (Tabela 3). A possível explicação para este fato, segundo Beaty et al. (1994), seria que animais sob suplementação diariamente ou três vezes por semana não apresentam diferenças no tempo dispendido em atividade de pastejo. Em contraste, Bohnert et al. (2002b) observaram redução no consumo de MS total e de pasto à medida que a frequência de fornecimento do suplemento reduziu, principalmente, quando houve maior intervalo entre a suplementação.

Tabela 2 - Composição bromatológica (\% MS) e digestibilidade in vitro da matéria seca (DIVMS) dos suplementos e do pasto

\begin{tabular}{lccr}
\hline Item & \multicolumn{2}{c}{ Suplemento } & \\
\cline { 2 - 3 } & Autocontrole & Frequência & Pasto ${ }^{1}$ \\
\hline Matéria seca (\%) & 91,36 & 90,35 & 11,24 \\
Matéria orgânica (\%MS) & 94,66 & 93,66 & 88,76 \\
Proteína bruta (\%MS) & 30,33 & 31,70 & 5,66 \\
Nitrogênio não-proteico & 69,86 & 33,89 & 38,72 \\
(\%N total) & & & \\
Extrato etéreo (\%MS) & 2,39 & 1,65 & 0,98 \\
Carboidratos totais (\%MS) & 60,31 & 61,94 & 82,12 \\
Fibra em detergente neutro & 39,82 & 39,15 & 73,67 \\
(\%MS) & & & \\
FDNi (\%MS) & 1,48 & 1,75 & 40,35 \\
Carboidratos não-fibrosos & 22,12 & 21,17 & 8,45 \\
(\%MS) & & & \\
Fibra em detergente ácido & 11,86 & 17,18 & 49,07 \\
(\%MS) & & & \\
Lignina (\%MS) & 3,67 & 3,61 & 6,00 \\
DIVMS (\%MS) & 64,20 & 64,54 & 47,65 \\
\hline 1Extrusa & & &
\end{tabular}

A estratégia de suplementação $(\mathrm{P}<0,10)$ teve efeito significativo somente sobre a digestibilidade aparente total da MS e foi maior nos animais que consumiram o suplemento tipo autocontrole (Tabela 4), o qual apresentou em sua formulação maior nível de ureia (Tabela 1). Assim, os requerimentos de $\mathrm{NH}_{3}$ dos microrganismos ruminais podem ter sido atendidos de forma mais rápida, em razão da alta degradabilidade da ureia, que ao chegar no rúmen, é rapidamente hidrolisada a $\mathrm{NH}_{3}$.

As frequências de suplementação estudadas não afetaram $(\mathrm{P}>0,10)$ a digestibilidade aparente total dos componentes. Resultados variados sobre os efeitos da frequência de suplementação sobre a digestibilidade total da MS têm sido observados na literatura. Farmer et al. (2001) observaram redução linear na digestibilidade quando forneceram os suplementos em menor frequência aos animais em menor frequência. De forma contrária, Beaty et al. (1994) verificaram maior coeficiente de digestibilidade nos animais sob suplementação três vezes por semana em comparação com a distribuição diária. De forma similar às observações deste estudo, Bohnert et al. (2002a) não verificaram efeito da frequência de suplementação sobre a digestibilidade da MS.

O aumento na digestibilidade observado por Beaty et al. (1994) foi associado ao menor consumo de forragem e ao maior tempo de retenção do alimento no trato gastrintestinal. Por outro lado, a sustentação da digestibilidade total da MS comprova a capacidade dos ruminantes em tamponar os efeitos do suprimento de nutrientes em menor frequência (Farmer et al., 2004). Neste contexto, segundo Bohnert et al. (2002b), em comparação a fontes ricas em proteína não-degradável no rúmen, o fornecimento de alimentos ricos em proteína

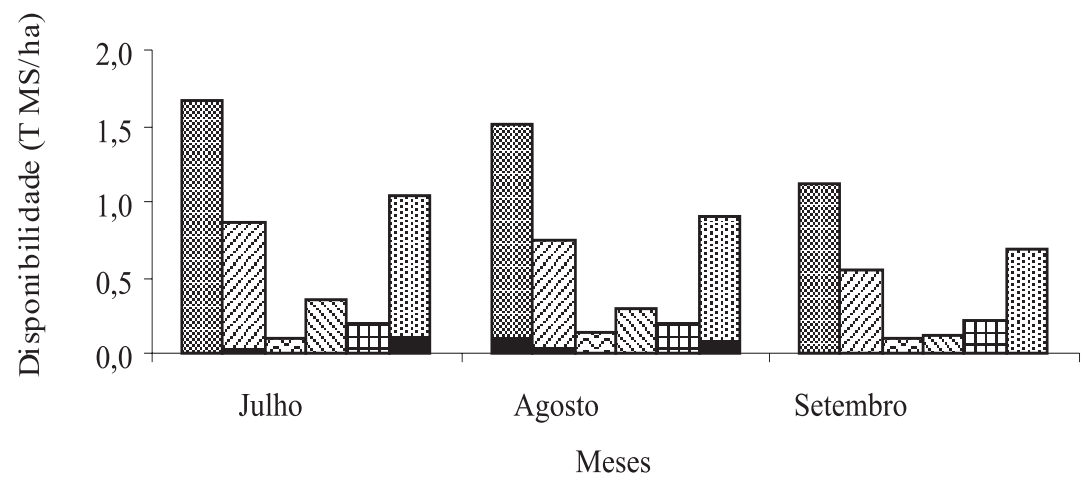

Figura 1 - Disponibilidade de MS total (MST) e potencialmente digestível (MSpD), de folha verde (MSFOV), de folha seca (MSFOS), de colmo verde (MSCOV) e de colmo seco (MSCOS) do pasto. 
degradável no rúmen pode reduzir as flutuações de nitrogênio ruminal que podem ocorrer quando grandes quantidades de suplemento são fornecidas, como no caso da menor freqüência de suplementação.

O fornecimento de suplemento autocontrole propiciou a digestibilidade aparente ruminal de $\mathrm{PB}(\mathrm{P}<0,10)$ mais que as frequências estudadas. Esse fato pode indicar que os animais apresentaram maiores perdas de proteína na forma de $\mathrm{NH}_{3}$, o que pode ser indicativo de excesso de consumo de PDR. De fato, as maiores concentrações de $\mathrm{NH}_{3}$ ruminal (Figura 3) foram observadas com o fornecimento do suplemento autocontrole e com a consequente maior

Tabela 3 - Consumo dos nutrientes em bovinos em pastejo

\begin{tabular}{|c|c|c|c|c|c|c|c|c|c|}
\hline \multirow[t]{2}{*}{ Item } & \multicolumn{5}{|c|}{ Frequência } & \multirow[t]{2}{*}{ CV (\%) } & \multicolumn{3}{|c|}{ Contraste $^{1}$} \\
\hline & $\mathrm{AC}$ & 3 vezes & 5 vezes & 6 vezes & 7 vezes & & ACF & Linear & Quadrático \\
\hline & \multicolumn{5}{|c|}{$\mathrm{kg} / \mathrm{dia}$} & & & & \\
\hline Matéria seca total & 6,18 & 6,12 & 6,18 & 6,17 & 6,20 & 8,7 & 0,972 & 0,826 & 0,938 \\
\hline Matéria seca do pasto & 5,23 & 5,25 & 5,26 & 5,26 & 5,27 & 10,4 & 0,848 & 0,440 & 0,536 \\
\hline Matéria orgânica & 5,58 & 5,50 & 5,51 & 5,51 & 5,52 & 8,8 & 0,575 & 0,443 & 0,532 \\
\hline Proteína bruta & 0,63 & 0,62 & 0,62 & 0,62 & 0,63 & 6,3 & 0,506 & 0,570 & 0,698 \\
\hline Extrato etéreo & 0,08 & 0,07 & 0,07 & 0,07 & 0,07 & 8,6 & 0,804 & 0,867 & 0,708 \\
\hline Carboidratos totais & 5,20 & 5,15 & 5,16 & 5,16 & 5,16 & 9,2 & 0,643 & 0,438 & 0,531 \\
\hline Fibra em detergente neutro & 4,25 & 4,22 & 4,23 & 4,23 & 4,23 & 9,5 & 0,697 & 0,441 & 0,525 \\
\hline \multirow[t]{2}{*}{ Carboidratos não-fibrosos } & 0,96 & 0,93 & 0,93 & 0,93 & 0,93 & 8,1 & 0,378 & 0,449 & 0,508 \\
\hline & \multicolumn{5}{|c|}{$\% \mathrm{PV}$} & & & & \\
\hline Matéria seca total & 2,21 & 2,22 & 2,21 & 2,17 & 2,20 & 9,1 & 0,927 & 0,747 & 0,514 \\
\hline Matéria orgânica & 1,99 & 2,00 & 1,97 & 1,94 & 1,96 & 8,5 & 0,757 & 0,621 & 0,744 \\
\hline Matéria orgânica do pasto & 1,66 & 1,70 & 1,66 & 1,64 & 1,66 & 9,9 & 0,934 & 0,681 & 0,772 \\
\hline Fibra em detergente neutro & 1,53 & 1,54 & 1,51 & 1,49 & 1,50 & 9,1 & 0,898 & 0,649 & 0,774 \\
\hline
\end{tabular}

${ }^{1} \mathrm{ACF}=$ autocontrole versus frequência; $\mathrm{L}$ e Q = efeitos de ordem linear e quadrático da frequência de suplementação.

Tabela 4 - Digestibilidade aparente total, ruminal e intestinal dos nutrientes em bovinos em pastejo sob suplementação em diversas frequências

\begin{tabular}{|c|c|c|c|c|c|c|c|c|c|}
\hline \multirow[t]{2}{*}{ Item } & \multicolumn{5}{|c|}{ Frequência } & \multirow[t]{2}{*}{ CV (\%) } & \multicolumn{3}{|c|}{ Contraste $^{1}$} \\
\hline & $\mathrm{AC}$ & 3 vezes & 5 vezes & 6 vezes & 7 vezes & & ACF & Linear & Quadrático \\
\hline & \multicolumn{5}{|c|}{ Total } & & & & \\
\hline Matéria seca & 62,28 & 60,94 & 58,70 & 57,70 & 59,12 & 3,5 & 0,062 & 0,103 & 0,105 \\
\hline Matéria orgânica & 60,78 & 62,34 & 58,88 & 56,51 & 55,83 & 5,8 & 0,187 & 0,274 & 0,275 \\
\hline Proteína bruta & 72,43 & 70,21 & 68,23 & 64,73 & 66,23 & 5,8 & 0,205 & 0,243 & 0,275 \\
\hline Carboidratos totais & 64,97 & 66,97 & 65,22 & 62,84 & 65,10 & 2,4 & 0,654 & 0,121 & 0,104 \\
\hline Fibra em detergente neutro & 68,66 & 70,12 & 68,47 & 66,36 & 68,20 & 3,4 & 0,956 & 0,127 & 0,139 \\
\hline \multirow[t]{2}{*}{ Carboidratos não-fibrosos } & 85,00 & 84,35 & 83,08 & 82,29 & 82,23 & 4,8 & 0,329 & 0,385 & 0,738 \\
\hline & \multicolumn{5}{|c|}{ Ruminal } & & & & \\
\hline Matéria seca ${ }^{2}$ & 68,33 & 69,09 & 69,11 & 68,48 & 69,05 & 13,7 & 0,901 & 0,967 & 0,947 \\
\hline Matéria seca ${ }^{2}$ & 72,21 & 73,16 & 72,86 & 72,66 & 71,72 & 1,1 & 0,264 & 0,241 & 0,536 \\
\hline Proteína bruta ${ }^{3}$ & 38,41 & 34,20 & 33,15 & 29,75 & 30,13 & 8,7 & 0,080 & 0,588 & 0,798 \\
\hline Carboidratos totais $^{2}$ & 86,24 & 87,70 & 86,95 & 87,02 & 87,14 & 1,8 & 0,593 & 0,784 & 0,758 \\
\hline Fibra em detergente neutro ${ }^{2}$ & 85,66 & 85,50 & 85,35 & 84,84 & 85,28 & 5,4 & 0,691 & 0,708 & 0,646 \\
\hline \multirow[t]{2}{*}{ Carboidratos não-fibrosos ${ }^{2}$} & 75,73 & 76,98 & 76,65 & 77,60 & 75,66 & 9,6 & 0,796 & 0,672 & 0,630 \\
\hline & \multicolumn{5}{|c|}{ Intestinal } & & & & \\
\hline Matéria seca ${ }^{2}$ & 31,67 & 30,91 & 30,89 & 31,52 & 30,95 & 30,3 & 0,901 & 0,860 & 0,778 \\
\hline Matéria orgânica ${ }^{2}$ & 3,79 & 3,84 & 4,14 & 4,34 & 4,28 & 14,6 & 0,264 & 0,833 & 0,913 \\
\hline Proteína bruta ${ }^{3}$ & 52,32 & 51,50 & 51,33 & 52,44 & 52,06 & 14,1 & 0,150 & 0,401 & 0,649 \\
\hline Carboidratos totais $^{2}$ & 13,76 & 12,30 & 13,05 & 12,98 & 12,86 & 31,3 & 0,796 & 0,124 & 0,464 \\
\hline Fibra em detergente neutro ${ }^{2}$ & 14,34 & 14,50 & 14,65 & 15,16 & 14,75 & 36,0 & 0,691 & 0,708 & 0,646 \\
\hline Carboidratos não-fibrosos ${ }^{2}$ & 24,74 & 23,02 & 23,35 & 22,40 & 24,34 & 10,4 & 0,593 & 0,865 & 0,849 \\
\hline
\end{tabular}

${ }^{1}$ ACF = autocontrole versus frequência; L e Q = efeitos de ordem linear e quadrático da frequência de suplementação; ${ }^{2} \%$ do total digerido. ${ }^{3} \%$ da quantidade que chegou no local. 
excreção urinária de nitrogênio na forma de ureia (Tabela 6). A digestibilidade aparente intestinal dos nutrientes não foi afetada $(P>0,10)$ pela estratégia de suplementação nem pelas frequências estudadas.

De acordo com Ørskov \& Tyler (1990), substratos disponíveis para a fermentação, juntamente com o pH ruminal, são os principais fatores determinantes da sobrevivência dos microrganismos no ecossistema ruminal, sobretudo a redução do $\mathrm{pH}$, causa isolada dos efeitos associativos negativos de diversos componentes da dieta sobre a digestibilidade da ração.

Os valores de $\mathrm{pH}$ (Figura 2) estiveram sempre acima do limite de 5,0 a 5,5 (Hoover, 1986) como inibitório à atividade dos microrganismos celulolíticos. Estudando diferentes frequências de suplementação, Farmer et al. (2004) também encontraram resultados semelhantes.

Os valores médios observados no dia em que os animais receberam suplemento foram de 6,78 $\pm 0,07 ; 6,76 \pm$ 0,$12 ; 6,68 \pm 0,14,6,72 \pm 0,06$ e 6,68 $\pm 0,11$, respectivamente, para autocontrole, 3 vezes/semana, 5 vezes/semana, 6 vezes/semana e diariamente. Quando o $\mathrm{pH}$ foi mensurado nos dias em que os animais não receberam suplemento (suplementação em menor frequência), os valores foram de: 6,54 \pm 0,13; 6,48 $\pm 0,15$ e 6,61 $\pm 0,07$, respectivamente, para as frequências 3 vezes/semana, 5 vezes/semana, 6 vezes/semana.

As concentrações médias observadas no dia em que os animais receberam suplemento foram de $34,57 \pm 10,98$; $30,37 \pm 11,46 ; 30,32 \pm 9,73 ; 28,00 \pm 11,78$ e 25,53 $\pm 6,54$ mg/dL de líquido ruminal, respectivamente, para autocontrole, 3 vezes/semana, 5 vezes/semana, 6 vezes/semana e diariamente (Figura 3). Quando a estimativa da concentração do $\mathrm{NH}_{3}$ foi realizada nos dias em que os animais não receberam suplemento (suplementação em menor frequência), os valores foram de: 14,65 \pm 5,78; 13,57 $\pm 5,30$ e 15,30 \pm 4,98 mg/dL de líquido ruminal, respectivamente, para as frequências 3 vezes/semana, 5 vezes/semana e 6 vezes/semana.

Em todos os tratamentos, e mesmo nos dias em que os animais não receberam a suplementação, o valor médio esteve acima de 5,0 mg/dL de $\mathrm{NH}_{3}$ (Griswold et al., 2003) e indica que a $\mathrm{NH}_{3}$ ruminal não limitou o crescimento microbiano em nenhuma das estratégias de suplementação. Mesmo nos dias em que os animais que não receberam suplementos, os níveis estiveram acima dos 10,0 mg/dL de líquido ruminal sugeridos por Leng (1990) como ótimo para apropriada fermentação em condições tropicais.

A maior concentração de $\mathrm{NH}_{3}$ ruminal nos animais que consumiram suplemento autocontrole pode ser atribuída à alta taxa de hidrólise da ureia. O fornecimento de suplemento com maior degradabilidade contendo fonte prontamente disponível de nitrogênio foi responsável pelas maiores concentrações de $\mathrm{NH}_{3}$ ruminal.

Não houve efeito $(\mathrm{P}>0,10)$ da frequência de suplementação sobre o fluxo de compostos nitrogenados e a eficiência microbiana (Tabela 5). Resultado similar foi encontrado por Bohnert et al. (2002a) ao avaliarem diferentes frequências de suplementação.

O valor médio para eficiência microbiana em g de $\mathrm{PBmic} / \mathrm{kg}$ de NDT consumido, foi 118,90 g PBmic/kg de NDT, próximo ao valor de $120 \mathrm{~g} \mathrm{PBmi} / \mathrm{kg}$ de NDT recomendado por Valadares Filho et al. (2006) como referência para condições tropicais. As eficiências microbianas expressas em g Nmic/kg MODR e Nmic/kg CTDR ficaram próximas às estimadas por Detmann et al. (2005) em bovinos em pastejo.

■ Dia de suplementação $\square$ Dia sem suplementação

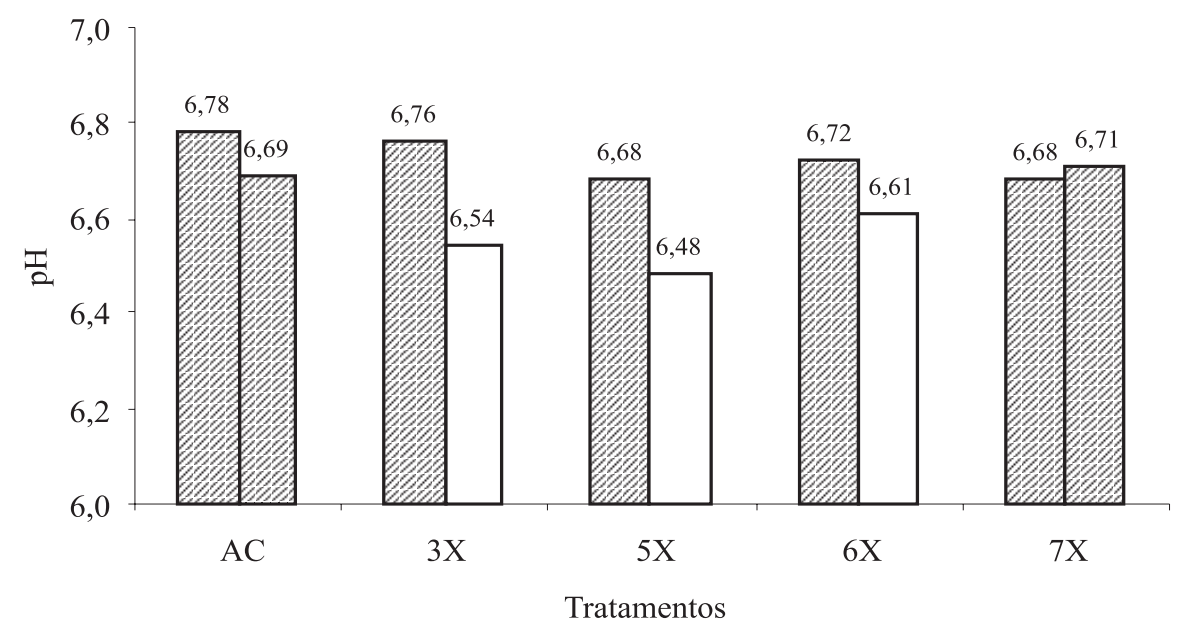

Figura 2 - Estimativa do pH do líquido ruminal obtida no dia da oferta do suplemento e no dia sem oferta do suplemento. 
■Dia com suplementação $\quad$ 口Dia sem suplementação

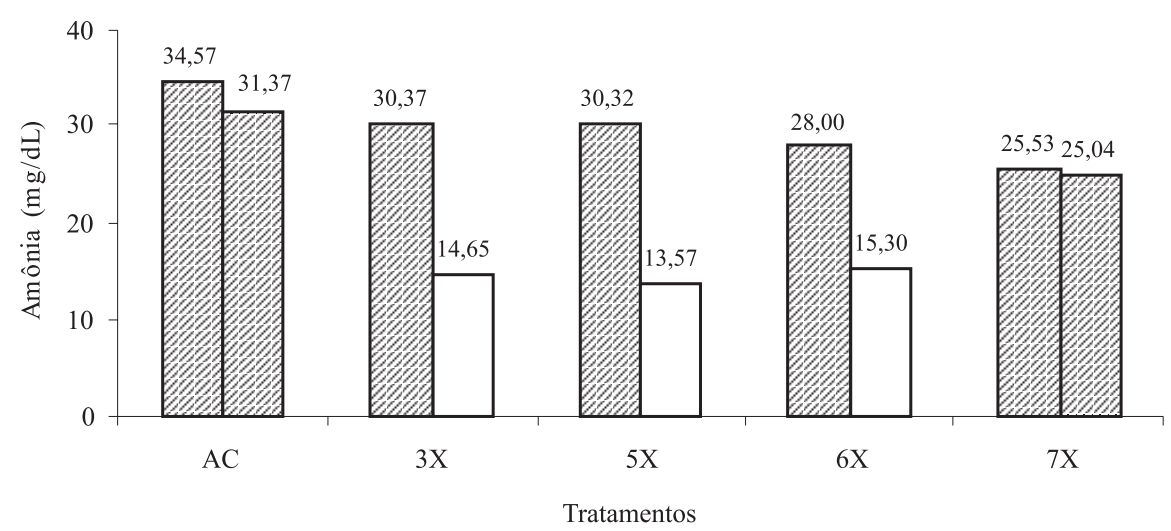

Figura 3 - Estimativa da concentração de $\mathrm{NH}_{3}$ do líquido ruminal obtida no dia do fornecimento do suplemento e no dia sem suplementação.

Tabela 5 - Fluxos de compostos nitrogenados microbianos (Nmic) e eficiência microbiana em bovinos em pastejo sob suplementação

\begin{tabular}{|c|c|c|c|c|c|c|c|c|c|}
\hline \multirow[t]{2}{*}{ Item } & \multicolumn{5}{|c|}{ Frequência } & \multirow[t]{2}{*}{ CV (\%) } & \multicolumn{3}{|c|}{ Contraste $^{1}$} \\
\hline & AC & 3 vezes & 5 vezes & 6 vezes & 7 vezes & & ACF & Linear & Quadrático \\
\hline \multirow[t]{2}{*}{ Nitrogênio microbiano (g/dia) } & 56,63 & 56,09 & 56,14 & 55,99 & 55,98 & 25,5 & 0,937 & 0,989 & 0,993 \\
\hline & \multicolumn{5}{|c|}{ Eficiência microbiana } & & & & \\
\hline $\begin{array}{l}\text { Matéria orgânica } \\
\text { (g Nmic/kg MODR) }\end{array}$ & 20,64 & 21,02 & 21,37 & 21,09 & 20,74 & 25,9 & 0,990 & 0,997 & 0,974 \\
\hline $\begin{array}{l}\text { Carboidratos totais } \\
\text { (g Nmic/kg CTDR) }\end{array}$ & 24,08 & 24,73 & 24,97 & 24,73 & 24,40 & 26,8 & 0,978 & 0,998 & 0,992 \\
\hline NDT (g PBmic/kg NDT) & 117,58 & 119,37 & 120,82 & 119,24 & 117,52 & 25,5 & 0,986 & 0,989 & 0,994 \\
\hline
\end{tabular}

${ }^{1} \mathrm{ACF}$ = autocontrole versus frequência; L e Q = efeitos de ordem linear e quadrático da frequência de suplementação.

A eficiência do crescimento microbiano depende da partição da energia para mantença e crescimento e relaciona-se inversamente (dentro de certos limites) ao tempo de permanência do microrganismo no ambiente ruminal (Nocek \& Russell, 1988). Neste sentido, os suplementos estudados podem ter possibilitado aporte de energia similar para o crescimento microbiano.

Observou-se efeito da estratégia de suplementação $(\mathrm{P}<0,10)$ sobre o nitrogênio ureico e sérico, cujos valores foram maiores nos animais que consumiram suplemento autocontrole (Tabela 6).

Apesar de não-significativo, a suplementação tipo autocontrole propiciou a ingestão de nitrogênio mais que a suplementação frequente, consequentemente, houve maior concentração de $\mathrm{NH}_{3}$, o que levou à maior excreção urinária de compostos nitrogenados. De fato, segundo Russell et al. (1992), a produção excessiva de $\mathrm{NH}_{3}$ e sua absorção ruminal aumentam a excreção de nitrogênio via urina. A quantidade, e principalmente a degradabilidade da proteína dietética, afeta o metabolismo da ureia
(Huntington et al., 2001), fato evidenciado pelas alterações nas concentrações de nitrogênio sérico ena excreção de NUR.

Nitrogênio total ingerido (NI) e excretado na urina (NUR) e nas fezes, nitrogênio ureico sérico e balanço de compostos nitrogenados não foram afetados $(\mathrm{P}>0,10)$ pelas frequências de suplementação (Tabela 6). Como o consumo de matéria seca total não foi alterado (Tabela 3), o nitrogênio ingerido também não diferiu entre as frequências de suplementação. Com relação à excreção de nitrogênio nas fezes, Currier et al. (2004) também não encontraram efeito da frequência de suplementação. Segundo Bohnert et al. (2002b), a frequência de suplementação tem pequeno efeito sobre a excreção de nitrogênio nas fezes.

A ausência de efeitos sobre a excreção de nitrogênio nas fezes pode estar relacionada às frequências de suplementação, que propiciam digestibilidade total similar à do nitrogênio. No entanto, Atkinson et al. (2010) forneceram suplemento a ovinos em dias alternados e verificaram maior excreção de nitrogênio, o que levou a aumento na digestibilidade total do nitrogênio. Verificaram 
ainda que a suplementação em dias alternados reduz a excreção de NUR, contribuindo para o aumento na retenção de nitrogênio, em comparação a ovinos alimentados diariamente. Segundo esses autores, embora aumentos na digestibilidade total do nitrogênio contribuam para aumentar o nitrogênio retido, a maior parte desta resposta decorre da redução na excreção de NUR.

Desta forma, a menor frequência de suplementação aumenta a síntese endógena de ureia para ser reciclada e retornar ao ambiente ruminal para ser usada pelos microrganismos, particularmente em dias sem suplementação (Atkinson et al., 2010). Assim, com base nesta afirmativa, se maior quantidade de NS for desviada para essa função produtiva, a excreção de NUR é diminuída.
Desta forma, como as excreções de nitrogênio fecal e nitrogênio ureico na urina não diferiram para as diferentes frequências, o balanço de nitrogênio nas duas formas apresentadas também não diferiu $(\mathrm{P}>0,10)$.

A concentração de nitrogênio sérico está positivamente correlacionda à ingestão de nitrogênio (Harmeyer \& Martens, 1980), assim o comportamento da nitrogênio sérico seguiu o mesmo da nitrogênio ingerido nas frequências avaliadas. Kennedy \& Milligan (1980) indicaram que mudanças na dieta, como alimentação restrita e/ou dietas com baixo teor proteico, podem alterar a permeabilidade do trato gastrointestinal para a ureia e mudar a regulação renal para sua excreção, o que pode ocorrer quando bovinos recebem suplemento em baixa frequência.

Tabela 6 - Nitrogênio total ingerido (NI), excretado na urina (NUR), nas fezes, nitrogênio ureico sérico e balanço de compostos nitrogenados em bovinos sob pastejo

\begin{tabular}{|c|c|c|c|c|c|c|c|c|c|}
\hline \multirow[t]{2}{*}{ Item } & \multicolumn{5}{|c|}{ Frequência } & \multirow[t]{2}{*}{$\mathrm{CV}(\%)$} & \multicolumn{3}{|c|}{ Contraste $^{1}$} \\
\hline & $\mathrm{AC}$ & 3 vezes & 5 vezes & 6 vezes & 7 vezes & & $\mathrm{ACF}$ & Linear & Quadrático \\
\hline Nitrogênio total ingerido (g/dia) & 101,49 & 98,67 & 98,84 & 98,70 & 97,69 & 5,0 & 0,247 & 0,792 & 0,768 \\
\hline $\begin{array}{l}\text { Nitrogênio excretado na urina } \\
\text { (g/dia) }\end{array}$ & 49,09 & 46,09 & 47,74 & 45,27 & 44,21 & 16,0 & 0,098 & 0,895 & 0,774 \\
\hline Nitrogênio nas fezes (g/dia) & 29,46 & 31,84 & 32,12 & 32,61 & 32,67 & 12,8 & 0,251 & 0,501 & 0,771 \\
\hline Nitrogênio ureico sérico (mg/dL) & 16,71 & 15,63 & 15,67 & 15,62 & 15,63 & 22,0 & 0,097 & 0,997 & 0,988 \\
\hline
\end{tabular}

${ }^{1}$ ACF = autocontrole versus frequência; L e Q = efeitos de ordem linear e quadrático da frequência de suplementação.

\section{Conclusões}

A suplementação tipo autocontrole de consumo aumenta a digestibilidade total da matéria seca, possivelmente pela maior concentração de amônia ruminal, que, apesar de propiciar maiores teores de nitrogênio no soro e na urina, não prejudica o balanço de compostos nitrogenados. Em condições tropicais, quando recebem suplemento em baixa frequência, bovinos de corte são eficientes em manter a concentração de $\mathrm{NH}_{3}$ do líquido ruminal em níveis adequados para o crescimento e a atividade microbiana. O fornecimento de suplementos autocontrole e a suplementação três vezes por semama são alternativas viáveis de manejo de suplementos proteicos, pois não prejudica as características ingestivas e digestivas nem eficiência microbiana e o balanço de compostos nitrogenados dos animais.

\section{Referências}

ATKINSON, R.L.; TOONE, C.D.; ROBINSON, T.J. Effects of ruminal protein degradability and frequency of supplementation on nitrogen retention, apparent digestibility, and nutrient flux across visceral tissues in lambs fed low-quality forage. Journal of Animal Science, v.88, n.2, p727-736, 2010.

BEATY, J.L.; COCHRAN, R.C.B.A.; LINTZENICH, B.A. et al. Effect of frequency of supplementation and protein concentration in supplements on performance and digestion characteristics of beef cattle consuming low-quality forages. Journal of Animal Science, v.72, p.2475-2486, 1994.

BOHNERT, D.W.; SCHAUER, C.S.; BAUER, M.L. et al. Influence of rumen protein degradability and supplementation frequency on steers consuming low-quality low-quality forage: I-Site of digestion and microbial efficiency. Journal of Animal Science, v.80, p.2967-2967, 2002a.

BOHNERT, D.W.; SCHAUER, C.S.; DELCURTO, T. Influence of rumen protein degradability and supplementation frequency on performance and nitrogen use in ruminants consuming lowquality forage: cow performance and efficiency of nitrogen use in wethers. Journal of Animal Science, v.80, p.1629-1637, $2002 b$.

CANESIN, R.C.; BERCHIELLE, T.T.; ANDRADE, P. et al. Desempenho de bovinos de corte mantidos em pastagem de capim-marandu submetidos a diferentes estratégias de suplementação no período das águas e da seca. Revista Brasileira de Zootecnia, v.36, n.2, p.411-420, 2007.

CHEN, X.B.; GOMES, M.J. Estimation of microbial protein supply to sheep and cattle based on urinary excretion of purine derivatives: on overview of technical details. Aberdeen: Rowett Research Institute/International Feed Research Unit, 1992. 21p. (Occasional publication).

CHIZZOTTI, M.L.; VALADARES FILHO, S.C.; VALADARES, R.F.D. et al. Determination of creatinine excretion and 
evaluation of spot urine sampling in Holstein cattle. Livestock Science, v.113, p.218-225, 2008.

CURRIER, T.A.; BOHNERT, D.W.; FALCK, S.J. et al. Daily and alterntive day supplementation of urea or biuret to ruminants consuming low-quality forage: I. Effects on cow performance and the efficince of nitrogen use in wethers. Journal of Animal Science, v.82, p.1508-1517, 2004.

DETMANN, E.; PAULINO, M.F.; VALADARES FILHO, S.C. et al. Níveis de proteína em suplementos para terminação de bovinos em pastejo durante o período de transição seca/águas: digestibilidade aparente e parâmetros do metabolismo ruminal e dos compostos nitrogenados. Revista Brasileira de Zootecnia, v.34, n.4, p.1380-1391, 2005.

FARMER, C.G.; COCHRAN, R.C.; NAGARAJA, T.G. et al. Ruminal and host adaptaptations to change in frequency of protein supplementation Journal of Animal Science, v.82, p.895-903, 2004.

FARMER, C.G.; COCHRAN, R.C.; SIMMS, D.D. et al. The effects of several supplementation frequencies on forage use and the performance of beef cattle consuming dormant tallgrass prairie forage. Journal of Animal Science, v.79, p.2276-2285, 2001.

HARMEYER, J; MARTENS, H. Aspects of urea metabolism in ruminants with reference to the goat. Journal of Animal Science, v.63, p.1707-1728, 1980.

HOOVER, W.H. Chemical factors involved in ruminal fiber digestion. Journal of Dairy Science, v.69, n.10, p.2755-2766, 1986.

HUNTINGTON, G.B.; POORE, M; HOPKINS, B. et al. Effect of ruminal protein degradability on growth and $\mathrm{N}$ metabolism in growing beef steers Journal of Animal Science, v.79, p.533-541, 2001.

GRISWOLD, K.E.; APGAR, G.A.; BOUTON, J. et al. Effects of urea infusion and ruminal degradable protein concentration on microbial growth, digestibility and fermentation in continuous culture. Journal of Animal Science, v.81, n.2, p.329-336, 2003.

KENNEDY, P. M.; MILLIGAN, L.P. The degradation and utilization of endogenous urea in the gastrointestinal tract of ruminants: A review. Canadian Journal of Animal Science, v.60, p.205-221, 1980.

LAZZARINI, I.; DETMANN, E.; SAMPAIO, C.B. et al. Intake and digestibility in cattle fed low-quality tropical forage and supplemented with nitrogenous compounds. Revista Brasileira de Zootecnia, v.38, n.10, p.2021-2030, 2009.
LENG, R.A. Factors affecting the utilization of "poor-quality" forages by ruminants particularly under tropical conditions. Nutrition Research Review, v.3, n.3, p.277-303, 1990.

MERTENS, D.R. Gravimetric determination of amylase treated neutral detergent fiber in feeds with refluxing in beakers or crucibles: Collaborative study. Journal of AOAC International, v.5, n.6, p.1212-1240, 2002.

MORAES, E.H.B.K.; PAULINO, M.F.; ZERVOUDAKIS, J.T. et al. Associação de diferentes fontes energéticas e protéicas em suplementos múltiplos na recria de novilhos mestiços sob pastejo no período da seca. Revista Brasileira de Zootecnia, v.35, n.3, p.914-920, 2006.

NOCEK, J.E.; RUSSELL, J.B. Protein and energy as an integrated system. Relation of ruminal protein and carbohydrates availability to microbial synthesis and milk production. Journal of Dairy Science, v.71, p.2070-2107, 1988.

ØRSKOV, E.R.; TYLE, M. Energy nutrition in ruminants. Cambridge: Elsevier Science Publishers, 1990. 146p.

NOLAN, J.V.; LENG, R.A. Dynamic aspects of ammonia and urea metabolism in sheep. British Journal of Nutrition, v.27, p.177, 1972.

RUSSELL, J.B.; O'CONNOR, J.D.; FOX, D.G. et al. A net carbohydrate and protein system for evaluating cattle diets: I - Ruminal fermentation. Journal of Animal Science, v.70, p.3562-61, 1992.

SILVA, D.J.; QUEIROZ, A.C. Análise de alimentos: métodos químicos e biológicos. 3.ed. Viçosa, MG: Editora UFV, 2002. 165p.

VALADARES, R.F.D.; BRODERICK, G.A.; VALADARES FILHO, S.C. et al. Effect of replacing alfalfa silage with high moisture corn on ruminal protein synthesis estimated from excretion of total purine derivatives. Journal of Dairy Science, v.82, n.11, p.2686-2696, 1999.

VALADARES FILHO, S.C.; PINA, D.S.; CHIZZOTTI, M.L. et al. Degradação ruminal da proteína dos alimentos e síntese de proteína microbiana. In: VALADARES FILHO, S.C.; PAULINO, P.V.R.; MAGALHÃES, K.A. (Eds.) Exigências nutricionais de zebuínos e tabelas de composição de alimentos BR-Corte. 1.ed. Viçosa, MG: UFV, DZO, 2006. 142p.

Van SOEST, P.J.; ROBERTSON, J.B. Analysis of forages and fibrous foods. Ithaca: Cornell University, 1985. 202p.

VERBIC, J.; CHEN, X.B.; MACLEOD, N.A. et al. Excretion of purine derivatives by ruminants. Effect of microbial nucleic acid infusion on purine derivative excretion by steers. Journal of Agricultural Science, v.114, n.3, p.243-248, 1990. 